\title{
Information Transmission and Innovation: Evidence from China
}

\author{
Xiaohui Wang ${ }^{1}$, Xin $\mathrm{Su}^{1}$, Rui Xue ${ }^{1}$ and Xueli Zhan ${ }^{2}$ \\ 1. Shandong University of Finance and Economics, Jinan, \\ Shandong 250014, P. R. China \\ 2 College of Management Economic, Tianjin University, Tianjin 300072, China \\ lzqsly@126.com; lg-jsx@126.com,cghnju@aliyun.com
}

\begin{abstract}
To better understand information transmission, we divided it into information acquisition and information absorption. With the data sourced from survey results, which involved 180 agricultural enterprises from in China, the paper conducts an empirical research on the relationship between and innovation performance. We found that that the promoting impact of information acquisition on enterprise innovation performance should be greater than that of information absorption. However, the difference is little.
\end{abstract}

Keywords: Information Transmission, Innovation Performance, Agricultural Enterprises

\section{Introduction}

Ferocious development of information and science technology are pushing the world economy into the era of information economy, while information has become an essential production factor, which brings corporations higher yields. When new technologies gradually emerged, and competitors multiply as well as products update fast, only those companies who can keep continuous innovation may success. In this era, corporations development depends directly on the information as well as its production transmission and application, which makes information become the core energy and lifeline of long-term growth.

Agriculture is the foundation of China's national economy. As the main business agent of modern agriculture, Agricultural enterprise is an effective carrier to realize the agricultural innovation. Agricultural enterprise plays a leading role in transforming China's agricultural economic development mode and promoting the optimization and upgrade of agriculture industry structure. Under the Information Age, the economic environment has presented characteristics such as rapid changes, fierce competitions and buyer's market. Commercial practices show that leading agricultural enterprises, by speeding up their products and services innovation, are trying to improve their core-competitiveness to adapt to market changes. Information is the key recourse of that innovation; whose transmission and sharing throughout enterprise management enable companies to keep sustainable innovation and competitive advantages. This research paper tries to provide a deep insight of what great influences that information transmission will bring to the agricultural enterprises' innovation performance, which might facilitate agricultural enterprises to optimize their information resources allocations on a more extensive thoughts and horizon to achieve better strategic performance and sustainable innovation.

Therefore, the objective of this research paper is to explore the impact of information transmission including information acquisition and absorption on agricultural enterprises' innovation performance in Shandong Providence of China. The paper is organized as follows: Section 2 reviews the related literature; Section 3 states the research variables, 
data and model setting; Section 4 conducts the empirical factor analysis and multivariate regression analysis; and Section 5 contains some conclusions. This study can be said to be quiet meaningful as an attempt consistent with the evidence-based policy in the field of national preferential agricultural policies.

\section{Literature Review}

Information transmission can help enterprises improve innovation performance. In this process of information transmission, the required new information is integrated and absorbed and the outdated or useless information is abandoned to encourage organization learning and technological innovation. Many researchers [1-3] think that good information transmission can promote the reallocation of existing resource or create new resource combinations, which will have positive impact on innovation outcome and process and help enterprises promote competitive advantage.

With more and more intense competition of markets, the technological innovations of enterprises have already had to rely on increasingly on information from social capital. Fangyu Song [4] found the survival and innovation of enterprise depend on the identification of market opportunity and reallocation of social resources when the market environment changes, which requires the enterprises to acquire information timely from their social capital and evaluate the value of all kinds of information to ensure the valuable information can be screened out to help the enterprise promote innovation performance. This view is supported by a series of empirical research [5-6].

Information acquisition is very important for agricultural enterprise to achieve products and services innovation and to make effective marketing strategies. Many scholars have made different empirical research on the relationship between information acquisition and innovation performance and most of the studies have shown that information acquisition have a positive effect on innovation performance [7-8]. The impact of enterprises' information absorption capability on firm innovation performance is mainly reflected in the prediction of future trends, the innovation enthusiasm, innovation costs, innovation frequency, the degree of acceptance and the speed of the new information [9-10]. Through information absorption, enterprises make effective information evaluation, assimilation, transformation and exploitation, finally improve innovation performance. Information transformation and exploitation determine the degree that enterprises' knowledge innovation and commercialization [11-12], which has more impact on innovation performance. Tsai [13] conducted an empirical study on the impact of information absorption on the innovation performance of food manufacturing industry, which found that the stronger the absorptive capacity of enterprise is, the easier for the enterprise to improve the commercial operation and technological innovation. This study is also confirmed by other research findings [14-21].

\section{Variables, Data and Model}

\subsection{Variable Measurements}

Information acquisition is the process that the agricultural enterprise discover, collect and organize of internal and external information resources. Information acquisition is an important part to achieve information transmission, which mainly affected by agricultural enterprises' information learning strength, speed, information search direction and the method. On the basis of document research and interview on the spot, information acquisition can be described through the following items: Q1-1: your enterprise can obtain the information of market change quickly; Q1-2: your enterprise can obtain the technology change information quickly; Q1-3: the cost of your enterprise obtaining the information is lower; Q1-4: the originality and precursor of your enterprises' information are superior.

Information absorption is the process that the agriculture enterprise reconfigure the 
information of different sources, different content and different forms, transfer the format to match the enterprise' resource and apply them to practice to realize information innovation. Information absorption is the most key part in the information transmission because only when agricultural enterprise applies the information to business practice, the information can create value. Information absorption is a complex process and the information receiver must have certain information stock, information structure and learning ability to absorb the information. On the basis of document research and interview on the spot, information absorption can be described through the following items: Q2-1: your enterprise can evaluate the value of acquired information; Q2-2: your enterprise has professional staff or department to organizing or storing the acquired information; Q2-3: your enterprise is able to integrate new information with original information quickly; Q2-4: your enterprise can improve the product technology or process with the new information; Q2-5 your enterprise can develop new products and market with the new information.

Based on the previous research, this research claims that the technology innovation of agricultural enterprises is the process that a new technology or product go through from idea generation to development and research, until to commercialization. Innovation performance refers to the output and efficiency in the process of agricultural enterprises' technology innovation. In general, scholars [22-25] evaluate innovation performance from the efficiency and effect of the enterprise's innovation activities. On the basis of document research and interview on the spot, the paper describes innovation performance through the following items: Q3-1: compared with the main competitors, the update speed of traditional business is faster; Q3-2: compared with the main competitors, the R\&D speed of new business is faster; Q3-3: compared with the main competitors, the number of new business is more; Q3-4: compared with the main competitors, the probability of success of new business is higher.

\subsection{Data Set}

The survey was designed by a team of researchers in Shandong University of Finance and Economics. After a pilot survey and refinement of the questionnaire, the survey was carried out in the period from July 2013 to June 2014.The sample is the Agricultural Enterprises of Shandong Province in China. We used the multistage sampling approach; first selected cities across Shandong Province, then selected representative agricultural enterprises in the cities. Data were collected by questionnaires which were given out to the senior executives of agricultural enterprises. Total of 570 questionnaires were sent out, and 271 were recovered. After careful screening, the number of effective questionnaire is 180 , and the effective recovery rate is $31.58 \%$.

\subsection{Model Setting}

Factor analysis is a statistical model used to remove redundancy and duplication from a set of observed and correlated variables. It is a data reduction tool to generate a lower number of common factors to represent correlated variables. The common factors are formed that are relatively independent of one another. For general factor analysis model, we assume that the number of original variables is $n$ with $p$ related indexes of each variable. After the standardization of original data, the means of variables are all 0 , and the variances are 1 . We use $\boldsymbol{X}$ to represent the standardized variables and $F_{l}, F_{2}, \cdots, F_{m}$ $(\mathrm{m}<\mathrm{p})$ to represent the standardized common factors.

Hence $\boldsymbol{X}=\left(X_{1}, X_{2}, \cdots, X_{p}\right)^{\prime}$ with $\boldsymbol{E}(\boldsymbol{X})=\boldsymbol{0}, \operatorname{cov}(\boldsymbol{X})=\Sigma . \boldsymbol{F}=\left(F_{1}, F_{2}, \cdots, F_{m}\right)^{\prime}(\mathrm{m}<\mathrm{p})$, with $\boldsymbol{E}(\boldsymbol{F})=\mathbf{0}, \operatorname{cov}(\boldsymbol{F})=I$ (each common factor independent with one another). Error term $\varepsilon=\left(\varepsilon_{1}, \varepsilon_{2}, \cdots, \varepsilon_{\mathrm{p}}\right)^{\prime}$ with $\boldsymbol{E}(\varepsilon)=\boldsymbol{0}, \operatorname{cov}(\varepsilon)=\Sigma_{\varepsilon}$, 
where $\Sigma_{\varepsilon}=\left(\begin{array}{ccc}\sigma_{11}^{2} & & 0 \\ & \ddots & \\ 0 & & \sigma_{p p}^{2}\end{array}\right)$.

The model $\left\{\begin{array}{c}X_{1}=a_{11} F_{1}+a_{12} F_{2}+\cdots+a_{1 m} F_{m}+\varepsilon_{1} \\ X_{2}=a_{21} F_{1}+a_{22} F_{2}+\cdots+a_{2 m} F_{m}+\varepsilon_{2} \\ \cdots \ldots \ldots \ldots \ldots \ldots \ldots \ldots \ldots \ldots \ldots \\ X_{p}=a_{p 1} F_{1}+a_{p 2} F_{2}+\cdots+a_{p m} F_{m}+\varepsilon_{p}\end{array}\right.$ is the factor model. Hence it can

be transformed to $\boldsymbol{X}=\boldsymbol{A} \boldsymbol{F}+\varepsilon$, where $A=\left[\begin{array}{llll}a_{11} & a_{12} & \cdots & a_{1 m} \\ a_{21} & a_{22} & \cdots & a_{2 m} \\ \cdots & \cdots & \cdots & \cdots \\ a_{p 1} & a_{p 2} & \cdots & a_{p m}\end{array}\right]$.

Based on the factor analysis theory, it is easy to obtain the proxy variable of Information Acquisition (IAC), Information Absorption (IAB) and Enterprise Innovation Performance (EIP), which is the fundamental step of the empirical analysis.

Researchers tend to use multivariate linear regression model to analyze empirical studies. In this article, the Multivariate linear regression model is also utilized to study the impact of information transformation (include information acquisition and information absorption) on the enterprise innovation performance. Based on the general Cobb-Douglas production function, the form of multivariate linear regression model can be constructed,

$$
E I P=\quad A I_{i}(i=1,2, \cdots, n)
$$

where $E I P_{i}$ is the proxy variable of Enterprise Innovation Performance (the $i$ th sample), $I T_{i}$ is the proxy variable of Information Transformation. Besides, $A_{i}$ is the other factors that can exert influences on the Enterprise Innovation Performance. Indeed, $A_{i}=A \cdot \varepsilon_{i}$ where $\varepsilon_{i}$ is the error term. According to the theoretical analysis, the information transformation (IT) can be divided into 2 variables, namely information acquisition (IAC) and information absorption (IAB). Hence, the equation (1) can be written as

$$
E I P_{i}=A \cdot I A C_{i}^{\gamma_{1}} \cdot I A B_{i}^{\gamma_{2}} \cdot \varepsilon_{\mathrm{i}}(i=1,2, \cdots, n)
$$

After taking logarithm of both sides in equation (2), the form of the multivariate linear regression model can be transformed as

$$
\begin{gathered}
\ln E I P_{i}=A+\gamma_{1} \ln I A C_{i}+\gamma_{2} \ln I A B_{i}+\mu_{i} \quad(i=1,2, \cdots, n) \\
\mu \sim N\left(0, \delta^{2} I_{n}\right) .
\end{gathered}
$$

Hence, the final model is set as

$$
E I P_{i}^{*}=C+C_{1} I A C_{i}^{*}+C_{2} I A B_{i}^{*}+\eta_{i}(i=1,2, \cdots, n)
$$

\section{Empirical Analysis}

\subsection{Empirical Factor Analysis}

The basic step of empirical analysis of the impact of information acquisition and information absorption on enterprise innovation performance is to obtain the data of the dependent and independent variables. According to the theory of factor analysis, the data of each proxy variable are acquired by Matlab 7.6. 
4.1.1 Empirical Factor Analysis of Information Acquisition: The information acquisition includes 4 factors. According to table 1 , it is easy to calculate the residual variance of each factor. We define $\mathrm{Q}_{1-1}$ as $\mathrm{X}_{1-1}, \mathrm{Q}_{1-2}$ as $\mathrm{X}_{1-2}, \mathrm{Q}_{1-3}$ as $\mathrm{X}_{1-3}$ and $\mathrm{Q}_{1-4}$ as $\mathrm{X}_{1-4}$. Hence the residual variances, $\operatorname{var}\left(e_{1-1}\right)=1-0.747=0.253, \operatorname{var}\left(e_{1-2}\right)=0.126, \operatorname{var}\left(e_{1-3}\right)=0.161$ and $\operatorname{var}\left(e_{1-4}\right)=0.194$ can be obtained. All the residual variances are less than 0.3 , which means the principal component analysis method of this factor analysis proves to be efficient.

Table 1. Communalities

\begin{tabular}{ccc}
\hline & Initial & Extraction \\
\hline Q1-1 & 1 & 0.747 \\
Q1-2 & 1 & 0.874 \\
Q1-3 & 1 & 0.839 \\
Q1-4 & 1 & 0.806 \\
\hline
\end{tabular}

Extraction Method: Principal Component Analysis.

Table 2 shows the details about the factor analysis of information acquisition. Common factor $1\left(F_{1}\right)$ accounts for $66.853 \%$ of all the variances, which is more than $50 \%$, meeting the requirement of regression analysis. Hence the variable of information acquisition can be represented by $F_{1}$.

Table 5. Total Variance Explained

\begin{tabular}{c|ccc|ccc}
\hline \multirow{2}{*}{ Component } & \multicolumn{3}{|c|}{ Initial Eigenvalues } & \multicolumn{3}{c}{ Extraction Sums of Squared Loadings } \\
\cline { 2 - 6 } & Total & $\begin{array}{c}\text { \% of } \\
\text { Variance }\end{array}$ & Cumulative \% & Total & $\begin{array}{c}\text { \% of } \\
\text { Variance }\end{array}$ & Cumulative \% \\
\hline 1 & 2.674 & 66.853 & 66.853 & 2.674 & 66.853 & 66.853 \\
2 & 0.655 & 16.376 & 83.229 & & & \\
3 & 0.397 & 9.923 & 93.152 & & & \\
4 & 0.274 & 6.848 & 100.000 & & & \\
\hline
\end{tabular}

Extraction Method: Principal Component Analysis.

4.1.2 Empirical Factor Analysis of Information Absorption: As can be seen from table 3, the information absorption consists of 5 factors, from Question 2-1 to Question $2-5$. The residual variance of each factor is as follows, $\operatorname{var}\left(e_{2-1}\right)=0.163, \operatorname{var}\left(e_{2-2}\right)=0.134$, $\operatorname{var}\left(e_{2-3}\right)=0.134, \operatorname{var}\left(e_{2-4}\right)=0.195$ and $\operatorname{var}\left(e_{2-5}\right)=0.168$. It is easy to conclude that the principal the factor analysis method of information absorption is also efficient.

Table 3. Communalities

\begin{tabular}{ccc}
\hline & Initial & Extraction \\
\hline Q2-1 & 1 & 0.837 \\
Q2-2 & 1 & 0.866 \\
Q2-3 & 1 & 0.866 \\
Q2-4 & 1 & 0.805 \\
Q2-5 & 1 & 0.832 \\
\hline \multicolumn{2}{l}{ Extraction Method: Principal Component Analysis. }
\end{tabular}

Obviously, from Table 4, common factor $1\left(F_{l}\right)$ explains $70.795 \%$ of all the variances, which is much more than $50 \%$, significantly meeting the requirement of regression analysis. Hence $F_{l}$ can be the proxy variable of information absorption. 
Table 4. Total Variance Explained

\begin{tabular}{c|ccc|ccc}
\hline \multirow{2}{*}{ Component } & \multicolumn{3}{|c|}{ Initial Eigenvalues } & \multicolumn{3}{c}{ Extraction Sums of Squared Loadings } \\
\cline { 2 - 6 } & Total & $\begin{array}{c}\text { \% of } \\
\text { Variance }\end{array}$ & Cumulative \% & Total & $\begin{array}{c}\text { \% of } \\
\text { Variance }\end{array}$ & Cumulative \% \\
\hline 1 & 3.540 & 70.795 & 70.795 & 3.540 & 70.795 & 70.795 \\
2 & 0.535 & 10.708 & 81.502 & & & \\
3 & 0.511 & 10.212 & 91.715 & & & \\
4 & 0.253 & 5.053 & 96.768 & & \\
5 & 0.162 & 3.232 & 100.000 & & \\
\hline \multicolumn{7}{c}{ Extraction Method: Principal Component Analysis. }
\end{tabular}

4.1.3 Empirical Factor Analysis of Enterprise Innovation Performance: Table 5 shows the communalities of the factor analysis of enterprise innovation performance. The residual variances can be calculated by the test results of communalities. The $\operatorname{var}\left(e_{3-1}\right)$ equals to $0.267, \operatorname{var}\left(e_{3-2}\right)=0.081, \operatorname{var}\left(e_{3-3}\right)=0.105$ and $\operatorname{var}\left(e_{3-4}\right)=0.101$. The values of the four variances are also less than 0.3 , which means the factor analysis is efficient.

Table 5. Communalities

\begin{tabular}{ccc}
\hline & Initial & Extraction \\
\hline Q3-1 & 1 & 0.733 \\
Q3-2 & 1 & 0.919 \\
Q3-3 & 1 & 0.896 \\
Q3-4 & 1 & 0.899 \\
\hline Extraction Method: Principal Component Analysis.
\end{tabular}

It is easier to confirm the common factor $1\left(F_{l}\right)$ meet the basic requirement of multivariate regression analysis, accounting for $74.816 \%$ of all the variances. Hence, according to the result of Table $6, F_{l}$ can be the proxy variable of enterprise innovation performance.

Table 6. Total Variance Explained

\begin{tabular}{c|ccc|ccc}
\hline \multirow{3}{*}{ Component } & \multicolumn{3}{|c|}{ Initial Eigenvalues } & \multicolumn{3}{c}{ Extraction Sums of Squared Loadings } \\
\cline { 2 - 7 } & Total & $\begin{array}{c}\text { \% of } \\
\text { Variance }\end{array}$ & Cumulative \% & Total & $\begin{array}{c}\text { \% of } \\
\text { Variance }\end{array}$ & Cumulative \% \\
\hline 1 & 2.993 & 74.816 & 74.816 & 2.993 & 74.816 & 74.816 \\
2 & 0.572 & 14.295 & 89.111 & & & \\
3 & 0.256 & 6.404 & 95.515 & & & \\
4 & 0.179 & 4.485 & 100.000 & & \\
\hline \multicolumn{7}{c}{ Extraction Method: Principal Component Analysis. }
\end{tabular}

Based on the principal component analysis, the data of multivariate regression analysis are obtained by empirical factor analysis. Hence, the proxy variables of information acquisition, information absorption and enterprise innovation performance are accepted to represent these variables.

\subsection{Empirical Multivariate Regression Analysis}

In the multivariate regression analysis of the impact of information acquisition and 
information absorption on enterprise innovation performance, ordinary least squares estimation is chosen as the estimation method of multivariate regression. And the multivariate test results are also acquired by Matlab 7.6.

Table 7. Multivariate Tests

\begin{tabular}{ccccc}
\hline Variable & Value & t-Value & Std. Error & Sig. \\
\hline $\mathrm{C}$ & 1.075 & 1.003 & 1.072 & 0.317 \\
$\mathrm{C}_{1}$ & $0.453^{*}$ & 6.220 & 0.073 & 0.000 \\
$\mathrm{C}_{2}$ & $0.375^{*}$ & 3.718 & 0.101 & 0.000 \\
\hline \multicolumn{5}{c}{. The value is significant at the 0.01 level }
\end{tabular}

According to the results of multivariate test (Table 7), the coefficients of Information Acquisition (IAC) and Information Absorption (IAB) are both significant, which are close to 0 , strongly reject the null hypothesis that there is no statistical relationship between IAC, IAB and EIP (enterprise innovation performance). Although the intercept term is statistically insignificant, the test results of multivariate linear regression tend to be ideal (the value of intercept term can be thought to be 0). Hence, the final model (equation 4) can be written as

$$
\begin{gathered}
E I P_{i}^{*}=0.453 I A C_{i}^{*}+0.375 I A B_{i}^{*}+\eta_{i} \quad(i=1,2, \cdots, 180) \\
\eta \sim N\left(0, \delta^{2} I_{180}\right)
\end{gathered}
$$

Virtually, the value of dependent variable can be seen as elastic coefficient because of the logarithm processing of equation (3). Table 6 shows the elastic coefficient of IAC to EIP is 0.453 , which means that the enterprise innovation performance would increase by $0.453 \%$ as information acquisition rises by $1 \%$ and the promoting impact is strongly significant. As for IAB, the elastic coefficient is 0.375 , which is less than that of IAC. The result proves that the promoting impact of information acquisition on enterprise innovation performance should be greater than that of information absorption. However, the difference is little and the promoting impact of information absorption on enterprise innovation performance is also significant. 1\% improvement in information absorption would bring about $0.375 \%$ increase in enterprise innovation performance.

\section{Conclusions}

With the data sourced from survey results, which involved 180 agricultural enterprises from Shangdong Province in China, the paper conducts an empirical research on the relationship between information transmission and innovation performance. We found that information transmission which includes information acquisition and absorption have a significant positive impact on the technological innovation performance of agricultural enterprises in China. Therefore, agricultural enterprises should pay attention to the construction of information transmission mechanism and channels to promote the speed and the efficiency.

One study limitation is that the sample scope of investigation and research only covered Shandong Province. The sample and data collection used in the research could only be considered as purposive sampling because of resource constraints. Another limitation is that the sample size is only 180, which may affect the conclusions generalization. To better understand the relationship between information transmission and innovation performance, data from more areas could be collected and analyzed. In the future, the research should increase the sample size and expand the investigation areas.

\section{ACKNOWLEDGEMENTS}

This work is supported by National Natural Science Foundation of China (Grant No. 61340043). This work is also partially supported by Program for Shandong Social Science 
Planning Management Project (Grant No. 11CJJJ03), Outstanding Young Scientist Research Award Foundation Project of Shandong Province (Grant No. BS2013SF033), Social Science Research Project of the Education Department of Shandong Province (Grant No. J11WG17) and Soft Science Research Project of Shandong Province (Grant No. 2013RKB01253)

\section{References}

[1] D. Miller, M. J. Fern and L. B. Cardinal, Academy of Management Journal, vol. 2, no. 308, (2007).

[2] S. Roper, J. Du and J. H. Love, Research Policy, vol. 961, (2008), pp. 6-7.

[3] M. Song, C. Droge and S. R. Hanvanich, Calantone, Strategic Management Journal, vol. 26, no. 259, (2005).

[4] F. Song, Journal of Northeastern University (Social Science), vol. 5, no. 416, (2012).

[5] J. Rhodes, P. Lok, Y. Y. R. Hung and S. C. Fang, Journal of Workplace Learning, vol. 4, no. 245, (2008).

[6] I. Maurer, V. Bartsch and M. Ebers, Innovation Performance and Growth, vol. 2, no. 157, (2011).

[7] P. J. Lane, J. E. Salk and M. A. Lyles, Strategic Management Journal, vol. 12, no. 1139, (2001).

[8] H. R. Yli, E. Autio and H. J. Sapienza, Strategic Management Journal, vol. 6, no. 587, (2001).

[9] P. J. Lane, B. R. Koka and S. Pathak, Academy of Management Review, vol. 4, no. 833, (2006).

[10] D. Lin, Editor, "Knowledge Management”, Publishing House of Electronics Industry, Beijing, (2005).

[11] Y. Deng, Journal of Industrial Organization, vol. 4, no. 1044, (2008).

[12] U. Lichtenthaler, Academy of Management Journal, vol. 52, no. 822, (2009).

[13] W. P. Tsai, Academy of Management Journal, vol. 5, no. 996, (2001).

[14] Z. Zhao and X. Wang, Management World, vol. 12, no. 58, (2007).

[15] Z. Zhan, Academy Research, vol. 3, no. 63, (2007).

[16] A. Fosfuri and J. A. Tribo, Elsevier (Special Issue), vol. 2, no. 173, (2008).

[17] A. Escribano, A. Fosfuri and J. A. Tribo, Research Policy, vol. 38, no. 96, (2009).

[18] X. Qian, Y. Yang and W. Xu, Management Word, vol. 5, no. 118, (2010).

[19] Y. L. Arie, M. C. Silvia and P. Carine, Organization Science-Organ ScI., vol. 1, no. 81, (2011).

[20] F. Tao, China Industrial Economics, vol. 1, no. 148, (2011).

[21] J. Zhang, A. Qi and Q. Xiong, Science of Science and Management of S.\&T, vol. 33, no. 5, (2012), pp. 55 .

[22] D. A. Nishiguchi, Administrative Science Quarterly, vol. 1, no. 128, (2003).

[23] J. Guan and X. Shi, China Mechanical Engineering, vol. 11, no. 1000, (2004).

[24] A. Escribano, A. Fosfuri and J. A. Tribo, Research Policy, vol. 38, no. 96, (2009).

[25] E. Kesidou and H. Romijn, World Development, vol. 1, no. 2004, (2008).

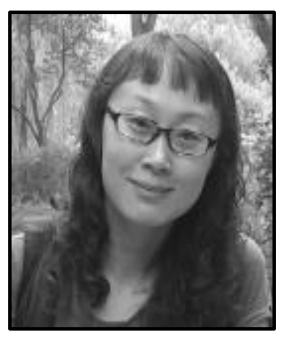

Xiaohui Wang, received her $\mathrm{Ph}$. D from Shandong University in 2010. She is currently an associate professor of Management. Her scientific interests include marketing management and managing complex systems.

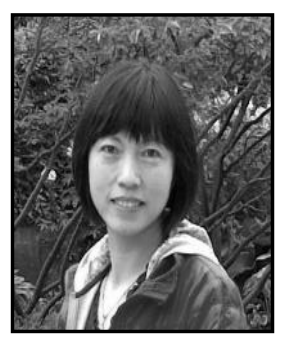

Xin Su, is a professor and a supervisor of Shandong University of Finance and Economics. Her scientific interests include quality and safety of agricultural products and industrial organizations in agriculture.

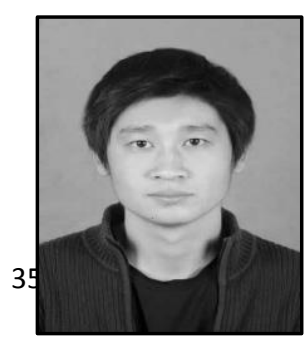

Rui Xue, is currently a master student of Shandong University of Finance and Economics. He will start his Ph.D program of Bond 
University in 2015. His scientific interests include spatial statistics, econometrics and data mining. 